\title{
Chapter 8 \\ When the Project Ends and Operations \\ Begin: Ensuring Safety During \\ Commissioning Through Boundary \\ Work
}

\section{Anne Russel and Stéphanie Tillement}

\begin{abstract}
Ensuring safe performance in inter-organisational projects involves managing a whole range of organisational, occupational and spatio-temporal boundaries. Regarding future safety, the commissioning phase is crucial. Drawing from the case of the commissioning of a new nuclear installation, we highlight the challenges associated with the transition between the project and operations and show the socio-material and temporal arrangements that support or hinder boundary work.
\end{abstract}

Keywords Nuclear industry • Inter-organisational projects • Commissioning • Boundary work $\cdot$ Process safety

\subsection{Introduction}

Since the 2000s, the safety implications of outsourcing work activities have become the subject of scrutiny from safety authorities, politicians and civil society. Most studies on that topic highlight a negative link between safety and outsourcing [7, 11]. With few exceptions [4], research conducted in the process industries focuses on permanent organisations (often maintenance) and does not study "from the inside" the way outsourced activities are actually carried out. Yet, lots of outsourced activities are now organised and coordinated within temporary configurations, as so-called interorganisational projects (IOP) [10]. There is a need to better understand the nature of interactions between the principal and the contractors in such organisational settings and how work is actually carried out and negotiated in relation to safety. Within IOPs, the design, construction and operation phases are generally carried out by actors from different companies. The transitions from one phase to another entail significant challenges for both project performance and future safety, as they require intense coordination between actors from various sectors and occupations. These key moments often disclose conflicts of interests, contractual disagreements and a need for continuous negotiation. Among them, commissioning is often considered

\footnotetext{
A. Russel $(\bowtie) \cdot S$. Tillement

IMT Atlantique, LEMNA, Nantes, France 
highly critical. It is the final opportunity to test the operational feasibility and safety in future operation by identifying and fixing all remaining deficiencies and errors [6]. Successful commissioning involves managing a whole range of boundaries, i.e. organisational, occupational and temporal [15]. Several authors have highlighted the role of boundary work [3] supported by actors or objects, but rarely in the context of high-risk IOPs and in relation to safety. In addressing our theoretical concerns, we develop the following research question to guide our empirical study: how and under which conditions can boundary work contribute to safe performance during the commissioning phase of projects?

To answer the research question, we investigate the commissioning of a new facility at a nuclear waste storage site. This enables us to draw attention to the specific difficulties encountered by the actors in this transition phase but also the socio-technical arrangements that are negotiated throughout this phase to manage boundaries and overcome these difficulties. Finally, we discuss the important lessons at the organisational and contractual dimensions.

\subsection{Outsourcing, Projects and Safety}

In the literature, outsourcing has been described as "the practice where a public or private organisation contracts another organisation or individual - usually through a process of competitive tendering - to undertake specified tasks, such as cleaning, transport or maintenance or even provision of a product" [7, p. 284]. Over the last 30 years, these practices have developed in high-risk organisations, mainly for economic or strategic reasons. It was seen by industries as a way to reduce labour costs and often driven by a strategy that focused on the core competences and/or sought enhanced organisational flexibility.

Outsourcing has often been identified as a causal factor of accidents. Some studies have highlighted the adverse effects on process and occupational safety, by highlighting the associated socio-technical risks (e.g. loss of internal know-how and competences for the principal) and organisational risks (e.g. excessive dependency on subcontractors with rare competences). Very recently, researchers have made the link between outsourcing, inter-organisational complexity and safety more explicit. Outsourcing can increase economic pressure, disorganisation and dilution of abilities [5]. In a context of high competition, contracting companies may take safety shortcuts and transfer risks to the lower supplier in the supply chain [4]. But this does not have to happen; under certain organisational conditions, outsourcing may foster operational safety and reliability. For example, long-term organisational relationships can contribute to development and maintenance of good social interactions between the different companies and groups of workers involved [5].

In line with these works, our research aims to better qualify organisational and professional conditions that may affect safety in IOPs, where work is distributed between multiple organisations and disciplines and performed in temporary settings. 
In the literature on complex projects, the links between performance, safety and interface management are a strong and recurrent issue [2, 9, 12]. The many boundaries (organisational, occupational, temporal, spatial) that generate several major problems in terms of communication and knowledge sharing [2, 14], role distribution and articulation work among various project phases and stakeholders or power and occupational jurisdictions [1]. Depending on the project and how it interacts with permanent organisations, the more problematic boundaries are not necessarily the ones between organisations but rather between occupational groups within a single organisation [12]. In enhancing coordination, many authors have highlighted the role played by specific individuals, known as boundary-spanners [14], who contribute to project performance through their ability to improve the sharing of information and knowledge [2] between the different organisations or professional groups within these projects. Boundary objects [8] appear to be just as important for transferring and translating knowledge in fragmented organisational contexts. They support ongoing negotiation between the various actors while acknowledging the specificities of each actor's activities, rhythms of work and skills [13, 16]. But, as shown by [1], artefacts may also reinforce boundaries and impede coordination when they are used to reassert authority and legitimacy over tasks.

We draw on this literature to investigate the case of a high-risk inter-organisational project carried out in a nuclear waste storage plant.

\subsection{A Safety-Critical Project: Building and Operating a New Facility at NucStor Plant}

Our study focuses on the 18-month commissioning phase of an ongoing IOP that aims at designing a new installation that will be dedicated to the reinforced control of nuclear waste packages. The plant in which the project takes place is operated by NucStor, ${ }^{1}$ an organisation specialising in nuclear waste storage. As such, it is responsible for the safety of the storage facilities and supervises the whole range of activities at the site. But most of the latter, including production, is outsourced. Production, which consists of the reception, control, conditioning and storage of waste packages, is entrusted to WasteCorp, an external company specialising in the construction and decommissioning of nuclear facilities. The course of the project has followed the classical steps described in the literature, i.e. design, construction and commissioning, each being led by a specific actor. NucStor's headquarters led the design phase, the construction was managed by a contractor under the supervision of NucStor's project team on site, and the commissioning was performed conjointly by the project team and WasteCorp. Our study focuses on this last phase, which is highly critical, due to the many socio-technical and organisational interfaces that are brought into play. The new unit will be integrated into the existing production process and, in line with the current situation, operated by WasteCorp. Its incorporation into

\footnotetext{
${ }^{1}$ For confidentiality reasons, all company names are pseudonyms.
} 
the existing socio-technical system is crucial for future safety. In completing this project, NucStor and its contractors are confronted directly with occupational and process safety issues since operating the facilities (both current and future) involves manipulating radioactive nuclear materials. Defining the future organisation of work requires cooperation and coordination between members of NucStor and contractors, notably during the commissioning phase. This requires articulating both current practices and knowledge, and those necessary to operate the future plant. In doing this, the tests performed during commissioning are crucial.

To understand how boundaries are managed to ensure safe performance, we draw on interviews with NucStor's project team, WasteCorp's operators and the project pilot. $^{2}$ We also observed tests and project meetings during the commissioning phase. Data were collected from September 2018 to July 2019 and followed by a qualitative analysis of interview transcripts and observation notes. Data coding was carried out manually and followed an iterative analysis process based on the comparison of field data with existing literature.

\subsection{Challenges Encountered in the Commissioning Phase}

As the future operator, WasteCorp, along with NucStor, plays a key role in the commissioning phase, which constitutes a test for the future operability and safety of the new installation. This involves facing emergent and often unexpected technical events that require specific technical and social skills to manage. From the very beginning of the commissioning phase, WasteCorp operators express difficulties in taking ownership of the facility and operating it as originally defined by the NucStor design team at headquarters.

Example of Unexpected Problems Encountered During an Inventory Test

An inventory test is carried out on an insulating box containing several waste packages. As the operator tries to move the packages from the box to the sorting area, he faces two problems. Firstly, the remote-control arm is not easy to manipulate and the clamps cannot pick up parcels that are too small (Fig. 8.1a). Secondly, when moving an oversized package, the package collides with the wall that separates the box from the sorting area, because the ceiling is too low (Fig. 8.1b).

\footnotetext{
2 The project pilot is employed by WasteCorp. Her role is to monitor the operators' commissioning work in the new installation and to support inter-organizational coordination between WasteCorp's operators and NucStor's project team.
} 


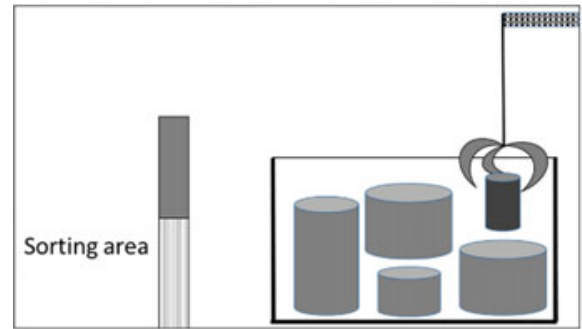

a) The remote control arm cannot pick up parcels that are too small

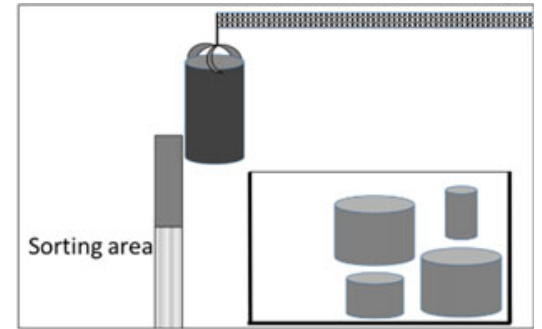

b) The ceiling is too low to allow the transport of large packages of waste in the sorting area

Fig. 8.1 Illustration of problems encountered during an inventory test

These problems arise from errors in the design and construction of the inventory room, which turns out to be too narrow. Alerts issued by operators regarding the handling of packages and the size of the room were not taken into account during design and construction. As a result, the operator has to enter the box to manually retrieve the parcels, which is theoretically forbidden.

Three main socio-technical issues are revealed, i.e. poor ergonomics of the installation, poor training of operators and poor communication between headquarters and the site, all having potential safety implications (Table 8.1).

Firstly, the operators complain that the work areas are too tight: once equipped with the regulatory protective suits, they lack adequate space to move around and properly handle the various tools and machines, which leads to additional handling

Table 8.1 Socio-technical problems and implications for safety

\begin{tabular}{l|l}
\hline Main challenges & Potential safety implications \\
\hline Ergonomics of the workplace & Imprecise handling of waste \\
\cline { 2 - 2 } & $\begin{array}{l}\text { Contact with radioactive } \\
\text { packages }\end{array}$ \\
\cline { 2 - 2 } & $\begin{array}{l}\text { Handling time too long in } \\
\text { contaminated areas }\end{array}$ \\
\hline Training of operators & $\begin{array}{l}\text { Partial knowledge of risks and } \\
\text { preventive measures }\end{array}$ \\
\hline & $\begin{array}{l}\text { Lack of monitoring and } \\
\text { traceability of control } \\
\text { activities }\end{array}$ \\
\hline Communication & $\begin{array}{l}\text { Poor management of key } \\
\text { interfaces for future process } \\
\text { safety }\end{array}$ \\
\cline { 2 - 2 } & $\begin{array}{l}\text { Little reactivity in the face of } \\
\text { emergent technical issues }\end{array}$ \\
\hline & Potential lack of transparency \\
\hline
\end{tabular}


time. Some tools are poorly designed and unusable as built. More importantly, this compels operators to develop deviant practices (some of which are theoretically prohibited) which leads to unexpected occupational and process safety issues.

Secondly, the operation of the new facility requires developing new skills associated with the new techniques and activities. The operators feel they are left to themselves in the process of acquiring these new skills and so must learn by trial and error on the job. Several reasons are advanced: lack of dedicated training times because of production pressures and insufficient support from hierarchy, principal and suppliers, non-recognition of the increased technical complexity and difficulties in complying with regulatory work (fulfilling the new operating procedures provided by design teams).

Finally, communication difficulties between headquarters and the site are revealed during commissioning. On the one hand, the design team is critical to the on-site project team and operators, who, according to designers, do not fully comply with their technical directives and requirements. Concretely, this is reflected in the imperative tone of their e-mails, their attitude of "principal" and their indifference to the technical constraints experienced by the operators in the field. On the other side, both the NucStor project team on site and WasteCorp operators express difficulties in communicating with headquarters members who are accused of having too abstract a vision of the installation, of not taking into consideration the technical feasibility of the current tools and of not visiting the site often enough. These attitudes, added to the geographic distance, tend to reinforce within NucStor the fault lines between the "people on the spot" and "the people at headquarters".

These problems have safety implications that can be observed in the case of projects involving workers belonging to the same company. But they tend to be reinforced in the face of outsourcing due to the multiplicity of interfaces.

In the face of these difficulties, NucStor and Wastecorp employees have conjointly and progressively developed and refined structural and operational local arrangements to manage interfaces and pursue their activities during the commissioning of the new installation.

\subsection{Boundary Work for Improved Reliability}

Early in the commissioning phase, the actors have engaged in intense boundary work, defined as all the socio-material arrangements and devices carried out to manage the many interfaces and associated risks during the commissioning phase. It relies on three key levers: individual, material and temporal.

At the beginning of the commissioning phase, a project team was set up on site to enhance integration and coordination between steps and stakeholders. It gathers NucStor representatives with specific key expertise and a project pilot from WasteCorp at the interface between the organisations. The analysis shows that the project pilot acts as a boundary spanner between the NucStor project team and the WasteCorp operators. Thanks to her "double hat", the project pilot benefits from 
the confidence of both companies, which enables her to easily communicate the instructions coming from the client and the requests and needs formulated by the operators. Her position supports inter-organisational coordination by allowing fluid and rapid interactions between the NucStor project team and WasteCorp operators. As contractors, WasteCorp operators must not receive direct instructions from the NucStor project team, so by integrating the project pilot with the project team, NucStor can also indirectly transmit instructions to operators, while avoiding perceptions of interference. As a trained engineer and manager of the operators in charge of commissioning, the project pilot also shares a professional experience on the ground with the WasteCorp operators, which is very valuable to the project team. During the project meetings, she is considered to be a fully fledged member capable of understanding the theoretical operation of the installation's different processes. At the same time, her daily involvement in the commissioning activity and her ability to provide permanent support for the operators' work enables her to develop strong expertise in the materiality of the installation and its constraints and to acquire professional legitimacy in the eyes of the operators.

Throughout the commissioning phase, the installation itself constitutes a boundary object between two occupational groups that each have different visions of the commissioning's times: NucStor engineers and WasteCorp production operators. While for the project team, commissioning is the end of the project; it represents for the operators the beginning of their new production activity. The materiality of the installation helps operators and engineers in managing and solving together the various problems encountered during commissioning (Box 2).

\section{The Installation as a Boundary Object Between NucStor and WasteCorp}

11:00am: During a technical test, the operator in charge of piloting the installation notices a design problem: a sensor is incorrectly positioned, blocking the operation of the monorail. He shares the problem with the project pilot who calls the NucStor maintenance manager to inform him of the problem.

3:30pm: The maintenance manager joins the operator on the installation. Together, they inspect the sensor problem: the operator explains that the sensor is malfunctioning because it sometimes rubs against the wall, blocking the operation of the monorail; the maintenance manager suggests unscrewing the sensor and positioning it in another place.

4:00pm: They agree that a modification must be made. The maintenance manager leaves the installation. He plans to make new supports for the sensors. The operator goes back to the control room and informs the project pilot of the decision. The project pilot integrates this modification request and modifies the test schedule accordingly.

By discussing the same object and confronting its materiality, NucStor project members and WasteCorp operators come to a better understanding of their respective problems. While each develops its own vision of the project and its constraints, the installation and the performed tests support the discussions on their respective roles regarding the commissioning and facilitate the cohesion of the different actors around 
the same objective. The installation helps in revealing the work carried out by the operators: by making their contribution in enacting the different processes visible to the engineers, the operators legitimise their role in the project and reaffirm their technical expertise vis-à-vis NucStor engineers.

Finally, our study reveals the positive contribution of the contractual relations established between NucStor and WasteCorp over almost 30 years due to the cooperation between both entities throughout the course of the project. These long-term relationships have allowed them to act jointly in the face of the many difficulties encountered during commissioning. The project has strengthened trust-based relationships between engineers and operators from both organisations engaged in the project. WasteCorp's operators have developed a sense of belonging to the project, which goes beyond their initial organisational affiliation. But paradoxically, the interorganisational cohesion within the project has created fault lines and reinforced the boundaries between the local and global levels, partly due to a lack of devices and tools to support communication and coordination.

\subsection{Discussion and Conclusion}

Literature on IOPs describes the challenges in terms of knowledge sharing and coordination between distinct stakeholders, with a strong focus on inter-organisational boundaries. As a transition between project and operation, commissioning is viewed as a crucial step for the success of a project and future safe operations, involving temporal boundaries. In this chapter, we have discussed the challenges collectively faced by actors during this transition and the many boundaries involved. In particular, we highlighted how a lack of involvement of the future user during the design and construction phases undermined the ability of operators to quickly learn how to operate the new installation and manage commissioning. But we have also shown the role played by boundary-spanners and boundary objects in overcoming these obstacles and successfully completing the commissioning. These arrangements supported boundary work, which was particularly efficient at the inter-professional and interorganisational levels. In our case, the existence of long-term contractual relations between client and contractor [9] also helped in managing these boundaries within the project, thanks to inter-individual relationships at the local level.

Finally, evidence from our research suggests that interfaces between the principal and its contractors are not necessarily the most problematic. When they are not considered, discussed and equipped throughout the project course, and notably in the final transition phase, intra-organisational and geographical boundaries prove to be just as crucial as inter-organisational ones for ensuring safety and performance of IOPs.

Acknowledgements This work was supported by the RESOH Chair. We are very grateful to NucStor and WasteCorp workers for their time and information. 
Ethical Statement This work adhered to the research ethics that are stipulated in the "RESOH Chair convention" that complies with relevant legislation regarding ethical conduct of research. Informed consent was obtained from participants, and all data has been anonymised.

\section{References}

1. B.A. Bechky, Sharing meaning across occupational communities: the transformation of understanding on a production floor. Organ. Sci. 14(3), 312-330 (2003)

2. P. Bosch-Sijtsema, L.-H. Henriksson, Managing projects with distributed and embedded knowledge through interactions. Int. J. Project Manage. 32(8), 1432-1444 (2014)

3. A. Langley, K. Lindberg, B. Mørk, D. Nicolini, E. Raviola, L. Walter, Boundary work among groups, occupations and organizations: from cartography to process. Acad. Manag. Ann. 13(2), 704-736 (2019)

4. V. McDermott, K. Henne, J. Hayes, Shifting risk to the frontline: case studies in different contract working environments. J. Risk Res. 21(12), 1502-1516 (2018)

5. V. Milch, K. Laumann, Sustaining safety across organizational boundaries: a qualitative study exploring how interorganizational complexity is managed on a petroleum-producing installation. Cogn. Technol. Work 20, 179-204 (2018)

6. P. Oedewald, N. Gotcheva, Safety culture and subcontractor network governance in a complex safety critical project. Reliab. Eng. Syst. Saf. 141, 106-114 (2015)

7. M. Quinlan, I. Hampson, S. Gregson, Outsourcing and offshoring aircraft maintenance in the US: implications for safety. Saf. Sci. 57, 283-292 (2013)

8. S.L. Star, J.R. Griesemer, Institutional ecology, translations and boundary objects: amateurs and professionals in Berkeley's Museum of Vertebrate Zoology, 1907-39. Soc. Stud. Sci. 19(3), 387-420 (1989)

9. W. Starbuck, M. Farjoun, Organizing at and beyond the limits. Organ. Stud. 28(4), 541-566 (2007)

10. S. Stjerne, J. Söderlund, D. Minbaeva, Crossing times: temporal boundary-spanning practices in interorganizational projects. Int. J. Project Manage. 37(2), 347-365 (2019)

11. A. Thébaud-Mony, Travailler peut nuire gravement à votre santé: Sous-traitance des risques, mise en danger d'autrui, atteintes à la dignité, violences physiques et morales, cancers professionnels, La Découverte, 2016

12. S. Tillement, C. Cholez, T. Reverdy, Assessing organizational resilience: an interactionist approach. Management 12(4), 230-264 (2009)

13. S. Tillement, J. Hayes, Maintenance schedules as boundary objects for improved organizational reliability. Cogn. Technol. Work 21(3), 497-515 (2019)

14. M.L. Tushman, Special boundary roles in the innovation process. Adm. Sci. Q. 22(4), 587-605 (1977)

15. J. Whyte, T. Nussbaum, Transition and temporalities: spanning temporal boundaries as projects end and operations begin. Proj. Manag. J. 51(5), 505-521 (2020)

16. E.K. Yakura, Charting time: timelines as temporal boundary objects. Acad. Manag. J. 45(5), 956-970 (2002) 
Open Access This chapter is licensed under the terms of the Creative Commons Attribution 4.0 International License (http://creativecommons.org/licenses/by/4.0/), which permits use, sharing, adaptation, distribution and reproduction in any medium or format, as long as you give appropriate credit to the original author(s) and the source, provide a link to the Creative Commons license and indicate if changes were made.

The images or other third party material in this chapter are included in the chapter's Creative Commons license, unless indicated otherwise in a credit line to the material. If material is not included in the chapter's Creative Commons license and your intended use is not permitted by statutory regulation or exceeds the permitted use, you will need to obtain permission directly from the copyright holder.

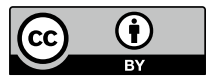

